\title{
LONG-TERM PRESERVATION OF THE PHYSICAL REMAINS OF THE DESTROYED BUDDHA FIGURES IN BAMIYAN (AFGHANISTAN) USING VIRTUAL REALITY TECHNOLOGIES FOR PREPARATION AND EVALUATION OF RESTORATION MEASURES
}

\author{
Georgios Toubekis $^{\mathrm{a}^{*}}$, Michael Jansen $^{\mathrm{b}}$, Matthias Jarke ${ }^{\mathrm{c}}$ \\ ${ }^{a}$ RWTH Aachen University, Information Systems Group, Ahornstr. 55, 52074 Aachen \\ ${ }^{\mathrm{b}}$ Research Center Indian Ocean, [RIO] Heritage, German University of Technology, Halban-Muscat, Oman \\ ${ }^{\mathrm{c}}$ Fraunhofer Institute for Applied Information Technology - FIT, 53754 Sankt Augustin, Germany
}

Commission II

KEY WORDS: UNESCO World Heritage, Immersive Virtual Reality, Bamiyan, Reconstruction, Authenticity

\begin{abstract}
:
In March 2001, the world's largest depictions of standing Buddha figures located in Bamiyan (Afghanistan) were destroyed during a campaign of the Taliban leadership against all non-Muslim heritage in the country. Bamiyan and its archaeological remains have been nominated a World Heritage also to commemorate the events of destruction the site has experienced over the centuries. More than fifteen years after the Giant Buddha figures turned into dust, the UNESCO Safeguarding campaign for the preservation of the Bamiyan World Heritage property has made considerable progress. Upon continued request by the local population and the national government, the international community is asked to contribute proposals for the future presentation of the physical remains including the options of reassembling the original fragments. The achievements and backlashes of the UNESCO campaign are discussed and a proposal is given, how virtual technology can contribute to the ongoing discussion regarding the future of the site. At a time when deliberate raids during military conflicts against heritage places have become commonplace, the Bamiyan case has become emblematic and is considered now a key turning point in the heritage community on the question, which roles reconstruction can have especially in the aftermath of conflict situations. It is argued that immersive virtual reality technologies offer the chance to investigate how values attributed to cultural heritage are produced and experienced among different stakeholder groups.
\end{abstract}

\section{INTRODUCTION}

\subsection{Heritage authenticity and new technologies}

Tangible cultural heritage artifacts are characterized by a sense of significance and meaning which is attributed to their physical components and the spatial and historical context from which they originate. Authenticity, as defined by the Operational Guidelines to the World Heritage Convention, is understood as the undisputed understanding on the credibility of the object's properties. Concepts of authenticity, on the other hand, differ among cultures. Consequently differs the notion of preserving "authentic" information sources expressed through a variety of attributes: original or genuine material substance (even incomplete), complete coherence of the original shape or preserving the locational setting. The material, as well as the immaterial aspects of heritage values, are embodied in the physical existence of the monument. Documentation and interpretation materials accumulated over long periods of time serve as a supplement to the principal source which is the monument itself, as long as the original monument is existent. However, once the original monument does not exist anymore, the role of documentation material changes significantly since it becomes now a primary source from which the values attributed to the (lost) heritage must be understood. The ability to understand the value attributed to the heritage artifact depends on the degree to which information sources about this value may be considered credible or truthful (Article 80 of the OG). In connection with digital documentation data sets, the demand of the Operational Guidelines become crucial for the conservation, restoration, and management of physical heritage resources, acknowledging that judgments about values attributed to cultural heritage have to rely on the credibility of related information sources. Evaluation of the credibility of digital resources differs among stakeholder groups within and across cultures (Metzger and Flanagin, 2013). With innovative digital technologies on the horizon, old concerns such as potential loss of authenticity through physical reconstructions are raised again. On the other hand, increasing natural and man-made threats to movable and immovable cultural heritage worldwide increase the awareness that digital reproduction technologies offer resilience potential in a yet unprecedented way such as the Cyark initiative of Project Anqa ${ }^{l}$ has shown.

This paper deals with the question how immersive virtual reality technologies can facilitate an inter- as well as intra-cultural communication process among various expert domains on the one hand and involved stakeholders on the other, based on the case of the future presentation of the site where once the Giant Buddha figures stood; to help bridging gaps and give guidance on crucial decisions to be made by policymakers and regional actors with regard to truthfulness of the reconstruction efforts. After an overview of the significance of the site, the rest of the paper is structured as follows. The UNESCO safeguarding campaign is summarized, the documentation and restoration work done so far is presented with a focus on the situation at the eastern niche where once the 38 meters Buddha stood. The

\footnotetext{
Corresponding author

${ }^{1}$ see details on Cyark's Project Anqa at: http://www.cyark.org/news/project-anqa-progresses-in-2016
} 
immersive virtual environment proposed is described and how it is aimed to support decisions on future preservation and presentation of the fragments. Finally, an outlook is given on future work with regard to a scientific method for identification of the original position of stone fragments based on geomorphology and geomagnetic measurements.

\subsection{Significance of the Bamiyan site}

The Giant Buddha figures marked the most western extension of the Gandhara school of Buddhist art that flourished from $2^{\text {nd }}$ to $7^{\text {th }}$ century CE in the area of today Eastern Afghanistan and Northern Pakistan. Due to the artistic expression of its mural paintings, Bamiyan became a genuine center for Buddhist art in the course $6^{\text {th }}-9^{\text {th }}$ century CE located on the trade routes between Central Asia and India. The ensemble of the Giant Buddha figures of Bamiyan has been known as the world largest depiction of a standing Buddha. Carved deeply into the soft conglomerate of the cliff during the second half of the $6^{\text {th }}$ century CE the socalled "Small" Eastern Buddha raised up $38 \mathrm{~m}$ in height until it was overtopped some decades later at the beginning of the $7^{\text {th }}$ century CE by the "Big" Western Buddha that once measured $55 \mathrm{~m}$. In between and around the two standing figures, cave complexes carved from the sedimentary rock served a large Buddhist community, as we know from the written records by the traveling Chinese monk Xuanzang who visited Bamiyan in 629 CE (Beal, 1884).

In the beginning of the $20^{\text {th }}$ century, the Délégation Archéologique Française en Afghanistan (DAFA) initiated scientific research on the site (Godard et al., 1928; Hackin and Carl, 1933) including photographic documentation of key elements. Bamiyan and its special cave art came into focus again in the second half of the 20th century (Miyaji, 1976, Tarzi, 1977, Klimburg-Salter, 1989). A detailed documentation of the site was realized by the Archaeological Mission to Central Asia of Kyoto University in 1970-1977 who documented the entire main cliff of the site making use of advanced stereo-photogrammetry of the time (Higuchi, 1984; Higuchi and Barnes, 1995). With the aid of the Government of India, a yearlong restoration campaign was initiated that prepared the site of the Bamiyan Big and Small Buddha as a major tourist attraction during the 1970's (ASI Archaeological Survey of India, 2002).

International intervention and protest could not prevent the complete destruction of the Giant Buddha figures ordered by the Taliban leadership in March 2001 during an iconoclastic rage against all non-Muslim Cultural Heritage in the country.

In 2004, the empty niches, the cave complexes of the main cliff, as well in the nearby valleys and the ruins of a historic city and fortification complex were nominated a UNESCO World Heritage Site according to the 1972 World Heritage Convention as Cultural Landscape and Archaeological Remains of the Bamiyan Valley, a serial nomination of eight larger and smaller areas representing artistic and religious developments from the $1^{\text {st }}$ to the $13^{\text {th }}$ century CE.

Today's archaeological remains are also "testimony to recurring reactions to iconic art" making the memorial value of these events - as expressed with criterion (vi) of the property nomination - a significant constituent of the Outstanding Universal Value (OUV) of this site.

\section{UNESCO/ICOMOS SAFEGUARDING CAMPAIGN FOR THE PRESERVATION OF THE BAMIYAN SITE}

A first damage assessment was initiated by UNESCO at the site of the destroyed Buddha figures directly after the fall of the Taliban regime (Santana, 2002). While in the Eastern $38 \mathrm{~m}$ Buddha niche a little of original plaster from the figure had survived the explosion, the Western $55 \mathrm{~m}$ Buddha figure had been destroyed entirely, leaving only giant heaps of rubble from the figures. A first concept for immediate safeguarding actions and long-term preservation of these fragments and the plaster remains was presented by (Petzet, 2002). Conservation activities started in 2003 with the UNESCO Campaign for the Preservation of the Bamiyan Site funded by the Government of Japan (Japan Center for International Cooperation in Conservation (JCICC), 2005). Since then various international teams have been active to document damages of archaeological remains, execute conservation measures and assist the national authorities in the implementation of an effective management system of the entire property, an endeavor difficult to achieve under the ongoing crisis situation in Afghanistan ${ }^{2}$.

2.1 Documentation of damages, conservation, and management of the World Heritage Site

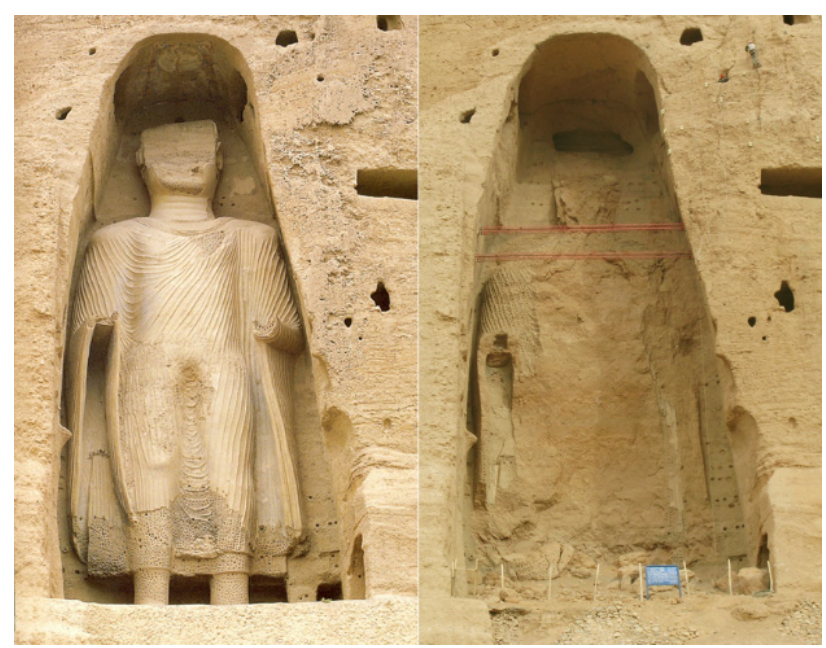

Figure 1. "Small" $38 \mathrm{~m}$ Eastern Buddha of Bamiyan before the destruction and empty niche in 2004

A survey team from the National Research Institute for Cultural Properties (NRICP) from Tokyo and Nara set up the coordinates for a permanent site reference system and produced a detailed landscape map from aerial pictures of the 1970's (Yamauchi et al., 2012a) and a detailed topographic map of the recent central Bamiyan valley. This also included 3D laser scans of the main cliff, the niches of the Giant Buddha's and several caves, in order to document the condition after the detonation, and to prepare site plan material for the next stages of the program including geophysical archaeological prospection to determine the extension of buried archaeological remains (Yamauchi et al., 2012b). The Japan Centre for International Cooperation in Conservation at NRICP initiated a comprehensive conservation intervention in selected cave structures in order to prevent further deterioration of the mural paintings based on a well-documented extensive damage assessment (Yamauchi et al., 2014, 2013). The scientific analysis revealed many new findings leading to a revised understanding of the way the cave settlement grew, and

\footnotetext{
${ }^{2}$ For an overview on the OUV of the site and UNESCO campaign see http://whc.unesco.org/en/list/208
} 
the materials used (Yamauchi and Suzuki, 2013). The RWTH Aachen Centre for Documentation and Conservation surveyed traditional architecture and the elements of the Cultural Landscape - i.e. a collection of the attributes of the OUV - as factual basis for the creation of a Cultural Master Plan, adopted by the Afghan authorities as planning basis for future development (ACDC, 2007; ACDC et al., 2013, 2011).

\subsection{Emergency consolidation of the Cliff}

Funded by the Culture Section of the German Foreign Office, ICOMOS Germany has been actively involved in the international UNESCO Safeguarding campaign for the Bamiyan World Heritage Site since the beginning. Primary aim has been the preservation of the remaining rock fragments of the destroyed figures (that were exposed to the forces of wind and rain), and their storage in temporary shelters. Furthermore, the stabilization of the detached mud plaster surfaces in situ was carried out, and treatment solutions for their preservation on the long term were studied.

On the lateral sides of the niches that were in danger to collapse completely due to the impact of the detonations, emergency consolidations were realized by Italian rock-climbers from RODIO Inc. (Margottini et al., 2005). After the cleaning of the niches from the rubble and in the preparation of the stabilization works for the rear side of the eastern niche, laser scanning was used to retrieve detailed plan material as the basis for the work of rock-engineers and restorers (Jansen et al., 2008). A comprehensive overview of these activities is given in (Petzet, 2009). All works are embedded in the recommendations of the UNESCO Expert Working Group for the Preservation of the Bamiyan Site which is coordinating the efforts of the different international teams. While the works at the site of the Western Buddha $(55 \mathrm{~m})$ niche are still ongoing, the cliff around the niche of Eastern Buddha (38m) has been stabilized with large and deep rock anchors and cleaned entirely from all stone rubble. In 20082010 , the rear side of the niche of the $38 \mathrm{~m}$ Buddha was consolidated, including pinning back of smaller or loose areas of rock by grouting in small and medium size stainless steel anchors. In some cases, the stabilization of larger pieces required significant anchoring of several meters into the cliff combined with the injection of cementitious grout into fissures in the rock behind the rear face of the niche (Margottini, 2014). The consolidation works at the $38 \mathrm{~m}$ Buddha niche were successfully completed in 2010, despite the deterioration of the overall security situation in the country.

\subsection{Restoration and long-term strategy for preservation of the fragments}

Beyond the stabilization works of the rear wall, ICOMOS Germany consolidated also the lower part of the Eastern Buddha niche. The partition walls of the three caves located there were blasted out from the massive explosion of 2001, leaving a large hole at the bottom rear side of the niche. These cave structures were restored through reconstruction of the destroyed partition walls between the caves using original rock material from the blasted rubble. This operation now prevents the falling down of loose rock material from the partly sculptured cave ceilings that had survived the explosion. For additional strength, a reinforced concrete slab on top of the reconstructed partition wall was constructed all along the rear side of the niche. Although these measures were carefully executed continuous fall of stone particles was observed as part of a natural erosion process of the entire cliff, partly caused by weather and nesting birds and due to the extremely delicate composition of the conglomerate rock material. This is composed out of sediments of varying grain size up to $20 \mathrm{~cm}$ interbedded with matrix-supported silt and sand, and extremely vulnerable to the exposition of water. Based on sample tests, the Technical University of Munich has therefore proposed a total impregnation of the salvaged fragments with silicate ester to enhance their physical strength and possible reuse for reconstruction purposes in the future. This option would require the shipment of those fragments out of Afghanistan for treatment in a specialized laboratory and thus seems out of reach for the foreseeable future.

In 2011, during the International Symposium commemorating ten years of the destruction of the Buddha Figures ${ }^{3}$ at UNESCO Headquarters in Paris, ICOMOS Honorary-President Michael Petzet put forward arguments to provide a protective canopy for visitors to the Buddha niche. This accounts especially for the reconstructed caves at the bottom of the rear side of the $38 \mathrm{~m}$ Buddha niche. Here, after completion of the restoration works, a small site interpretation room was opened exposing plaster fragments from the salvation operations and some interpretation panels, while larger pieces are covered under temporary shelters in some vicinity to the niches. It was proposed that this protective canopy should be non-obtrusive and "...following the front line of the former [figure] relief, a solution with two pillars at the site of the feet..." (Petzet, 2016, p. 89) in line with his long-standing argument that partial reassembly of the lost figures is not to be ruled out for the future.

Following an intensive debate, the World Heritage Committee encouraged the State Party, when considering options for the future treatment of the Buddha niches, to ensure that proposals are based on technical and financial feasibility studies which include an overall approach to conservation and presentation of the entire World Heritage property with respect to its Outstanding Universal Value (UNESCO World Heritage Centre, 2011).

Thanks to the significant progress achieved at the main cliff, more attention could be given to the other seven World Heritage areas in Bamiyan, including the ancient fortress of Shahr-e Zohak (the Red City) and the Islamic town of Shahr-e Gholghola from the Ghurid period, destroyed by Genghis Khan in 1221; both are in a precarious state of conservation today. Documentation and treatment could only be started there in 2010, after clearing large minefields that had been placed on the site during the long-year conflict periods. Also, more focus was placed on overall management procedures, especially on the implementation on the Cultural Master Plan Bamiyan, a summary of the cultural attributes of the valley and zoning proposal for its future development.

\subsection{Management deficiencies - lack of coordination among stakeholders, UNESCO, and advisory bodies}

In order to overcome the difficulties arising from the shortage of capacities and resources, the international experts involved in the UNESCO Safeguarding campaign initiated the so-called Bamiyan Expert Working Group already early in 2003, chaired by ICOMOS President Michael Petzet. The open discussion in the group involving Afghan experts in the annual meetings significantly contributed to the success of the UNESCO campaign and, for a long time, proved to be a suitable model for the preparation of large-scale interventions especially for a country like Afghanistan.

\footnotetext{
${ }^{3}$ Ten years on - remembering the tragic destruction of the giant Buddha statues of Bamiyan (Afghanistan) see: http://whc.unesco.org/en/news/718
} 
However, a critical self-evaluation after fifteen years has to conclude that this coordination mechanism reaches its limit when it is not able to achieve mutual consensus among its members. A crucial controversy about the future presentation of the main Buddha cliff turned out to be the key debate, unsolved to date. The arguments are bouncing between two poles: either leaving the site as-is, empty niches as a kind of war memorial, or attempting to rebuild part or all of a figure, a standpoint taken by the Afghan government and backed intensely by the local population - to have at least one figure revived from the ruins as an act of symbolic resurrection. Due to the still required intensive consolidation of the niche rear wall, this cannot be pursued for the Western (55m) Buddha for the foreseeable future. The situation at the Eastern $(38 \mathrm{~m})$ Buddha niche is considered more promising by the promoters of the second line of thought.

A protective canopy for visitors to the rearward caves in the eastern niche, preventing fall of small stone pieces, was pursued by the restoration team of the Technical University of Munich. It led to the construction of two reinforced pillars exactly on the location where once the "feet" of the original $38 \mathrm{~m}$ Buddha stood.

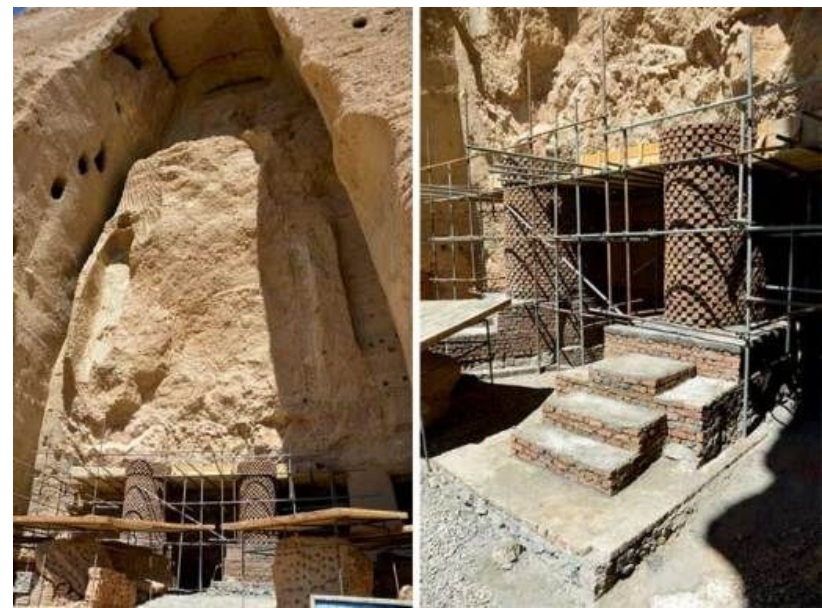

Figure 2. Situation at the bottom of the $38 \mathrm{~m}$ Buddha niche by end of 2014 (Source: UNESCO)

The technical realization aimed for additional structural stability of the rear wall in case of its unexpected structural failure. It was thought to provide a stable platform for partial reconstruction or reassembly of fragments of the Eastern $38 \mathrm{~m}$ Buddha. Although agreed with Afghan authorities prior to its execution, the exact design was not coordinated with UNESCO and the advisory bodies. The works were stopped in the middle, leaving a rather unfinished piece of intervention (Figure 2) that led to a broad controversial discussion within the international heritage community, and caused interruption of the UNESCO preservation project for almost two years. An independent technical advisory mission of ICOMOS International concluded the design realized was insufficient to meet the envisaged goals. In particular, the mission criticized the construction of a foundation for a support structure that is still to be developed and - even more important - not yet agreed upon by all involved stakeholders (ICOMOS, 2016). The fact, that the original feet of the $38 \mathrm{~m}$ Buddha statue were lost centuries ago, and that the pillars follow an outline introduced by the feet reconstruction of Indian restorers of ASI in the 1970's, was little noticed so far, adding another layer of complexity to the matter. The continued request of the Afghan authorities recently led to an initiative to have the future of the Bamiyan statues being discussed on a public symposium to which the entire world is open to submit a technical proposal: "inviting applicants to submit proposals for EITHER physical revitalization OR non-physical revitalization in the niche, in order to present the Government of Afghanistan with a balanced range of options reflecting the diverse spectrum of opinions about revitalization" (UNESCO, 2017).

\section{DIGITAL RECONSTRUCTION AND VISUALI- SATION FOR CONSERVATION AND MANAGEMENT}

The work in progress presented in this section is situated in the above reported context and pursues the assumption that digital technologies such as Virtual Reality (VR) can significantly contribute to achieving a view on the historical place of the destroyed Bamiyan figures, to which all stakeholders of the World Heritage Site can agree.

\subsection{Related work on digital reconstruction of the Bamiyan site and the Buddha figures}

Digital reconstructions of the destroyed Buddha figures have been explored since 2001 using a variety of techniques and methods. Photogrammetric procedures including algorithmic detection of surface geometry from historical pictures for both the $55 \mathrm{~m}$ and the $38 \mathrm{~m}$ Buddha (Grün et al., 2004; Grün and Hanusch, 2008) emphasized the methodology for generating high accuracy digital models entirely based on image matching methods. In contrast, a combination of methods for supporting conservators and engineers with detailed plan material during the ongoing conservation works within the UNESCO Safeguarding project has been followed by (Toubekis, 2009).

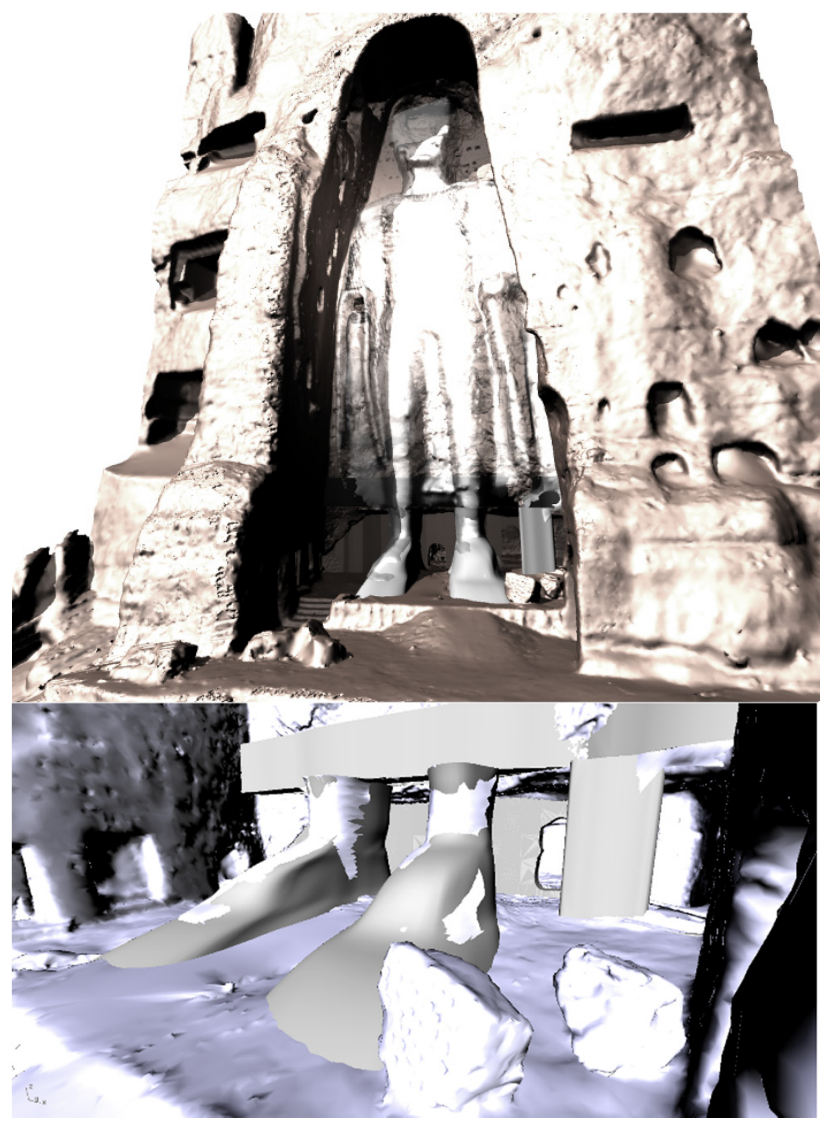

Figure 3. Simulation of the situation around the virtually reconstructed feet of the $38 \mathrm{~m}$ Buddha statue with simplified model of the niche modeled in Autodesk 3ds Max

A digitally created 3D model of the $38 \mathrm{~m}$ Buddha figure was superposed on a detailed $3 \mathrm{D}$ laser recording originating from the condition assessment for the restoration works. Here the focus 
was the recreation of the figure in 3D based on "elevating" highresolution iso-line contour plots in $2 \mathrm{D}$ that had been generated during a photogrammetric survey of the figure by Japanese researchers in the 1970 s of which, unfortunately, the original glass plate negatives were not available anymore. The resulting $3 \mathrm{D}$ surface of the destroyed figure is considered as an "envelope" into which any type of physical reconstruction proposal has to fit (Figure 4). It was produced as a communication tool and used in different presentation events, such as workshops of the Bamiyan Working Group and large-scale museum exhibitions (Toubekis et al., 2011).

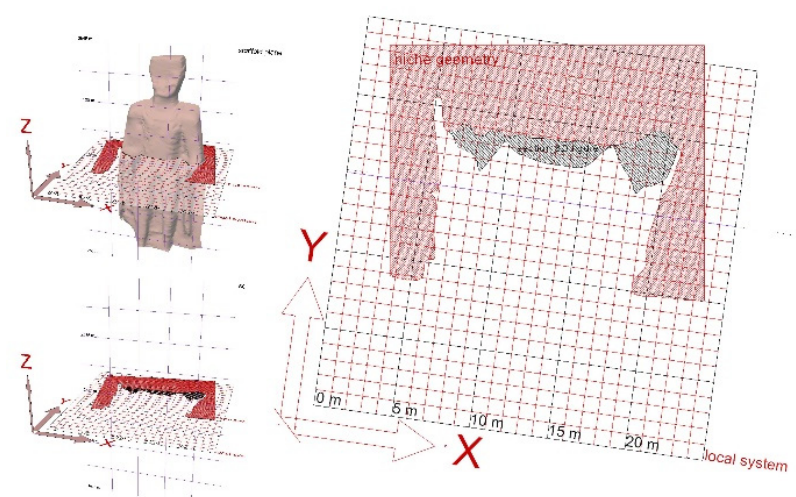

Figure 4. Steps to determine the contour outline of the destroyed $38 \mathrm{~m}$ Buddha figure in relation to the existing niche - average distance from the rear wall about $1.7-2 \mathrm{~m}$.

\subsection{The immersive VR environment in use}

The current application is realized with the Virtual-Reality for Scientific Technical Applications (ViSTA) framework that aims for enhancing scientific applications with VR methods and techniques for immersive visualization, thus enabling researchers from multiple disciplines to interactively analyze and explore their data in virtual environments. Immersive VR is a VR method in which the user becomes deeply involved in a virtual world. Immersion is defined as a psychological experience of submersion with a non-physical world, invoking a subjective sensual sensation of being present at a remote place (i.e. telepresence) for which the position of the spectators head in space is measured (infrared tracking), and the visual representation of projected images adapted in real time.

The ViSTA framework is developed and maintained by the Virtual Reality Group at RWTH Aachen University. It is composed of a set of open-source libraries written in C\# and is designed for system-independent management of display and input devices (i.e. tracking cameras or haptic devices). A stateof-the-art cluster mode allows for distributed execution of ViSTA applications on an array of computers, enabling seamless integration of multi-display environments. An application in ViSTA can thus run on a head mounted display, a 3D workbench and even the aixCAVE, a five-sided 3D immersive virtual reality environment at the Virtual Reality Center at RWTH Aachen University.

With a size of more than $5 \times 5 \mathrm{~m}^{2}$ for the rear floor projections, it is the world's largest implementation of such a system ${ }^{4 ;}$ It integrates 24 High-Definition DLP projectors (four per each side and eight for ground floor projection from below) driven by a 24-

\footnotetext{
4 A complete description of the aixCAVE system is found at http://vr.rwth-aachen.de/page/10/
}

node visualization cluster with 48 GPUs of the latest generation. The high level of immersion and an illusion of presence achieved are unique. Due to its capacity to accommodate up to five people, it opens up entirely new ways of collaborative interaction in virtual environments. The computational skills required for the design and implementation of an application in the programming language $L u a$ are a drawback of such a multi-purpose technical framework. Regrettably, applications realized in a more commonly used programming or gaming-framework (e.g. Unity) still lack the required cluster support and cannot be displayed in this environment.

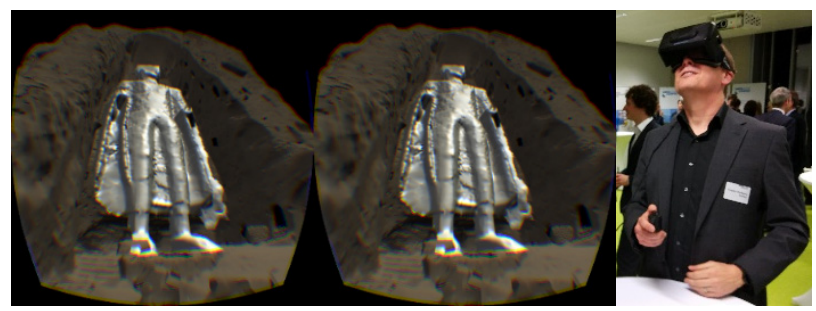

Figure 5. Stereoscopic rendering as shown via a head mounted device (HMD - Oculus Rift DK 2)

For the purpose of the current study an application is being designed that allows for an easy navigation within a scene composed of a model based on a) laser scan data of the entire Bamiyan cliff, b) laser scan data of the eastern 38 Buddha niche, c) digitally reconstructed caves at the bottom of the rear wall, and d) the digital model of the $38 \mathrm{~m}$ Buddha previously reconstructed from historical iso-line drawings. From this model, several instances show different aspects expressed by varying texture and geometry characteristics. Several cleaning, meshing, and simplification operations are required for reducing the complexity of the digital models in order to ensure reasonable frame rates across the different stereoscopic 3D visualization environments, especially the head-mounted device. This allows for a smooth visualization and good immersive experience of the entire scene; if required the originally colored $3 \mathrm{D}$ laser scan data set can always be activated to describe the complex geometry of the cliff in more detail at the cost of a significantly reduced frame rate.
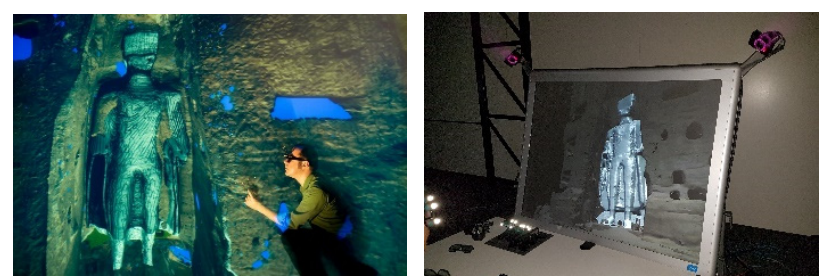

Figure 6. (left): Immersive 3D aixCave System (right): infrared head-tracked 3D workbench ${ }^{5}$

The Lua application is executed on a Dell Precision T7500 Quad Core 2,53 GHz CPU and $12 \mathrm{~GB}$ memory RAM with a Nvidia Quadro FX5800 GPU of 8GB graphic memory supporting seamless interaction with an immersive $3 \mathrm{D}$ workbench and a Head-Mounted Display (Figure 6 and 7) from the same computer. The application allows the handling of this scene that incorporates information coming from heterogeneous data sets, research results and historical sources. The experiences made so far with various user groups confirm the high immersive sensation and the strong feeling of telepresence of users. In

${ }^{5}$ for the purpose of this illustration stereo projection has been turned off for better visibility of the projected image 
individual cases, users even experienced effects of motion sickness described by (Behr et al., 2005) triggered by movements such as "dangerous leaning" across the top of the niche. In a future step, it is envisaged to allow for an integration of additional visual information augmenting the virtual experience with digital images from the site e.g. depictions of the salvaged fragments or other helpful context information.

\subsection{VR assisting discussion on physical reconstruction in heritage projects}

The use of virtual reconstructions in the context of physical restoration projects has been shown for a historic city gate by (Almagro, Vidal et al., 2015), to facilitate interpretation to the general public of complex geometric, spatial, structural and temporal relationships with information originating from a variety of sources (i.e. laser scan, historical plans and pictures). Digital augmentation of measurement data from complex heritage sites for building phase visualization facilitates interdisciplinary research and the level of understanding of archaeological findings for the general public (Landes et al., 2015). Possibilities of Virtual Anastylosis based on computation analysis of fragments have been demonstrated in the domain of Archaeology, relying on identification of significant Roman column fragment features that can be indexed in a hierarchical manner (Canciani et al., 2013).
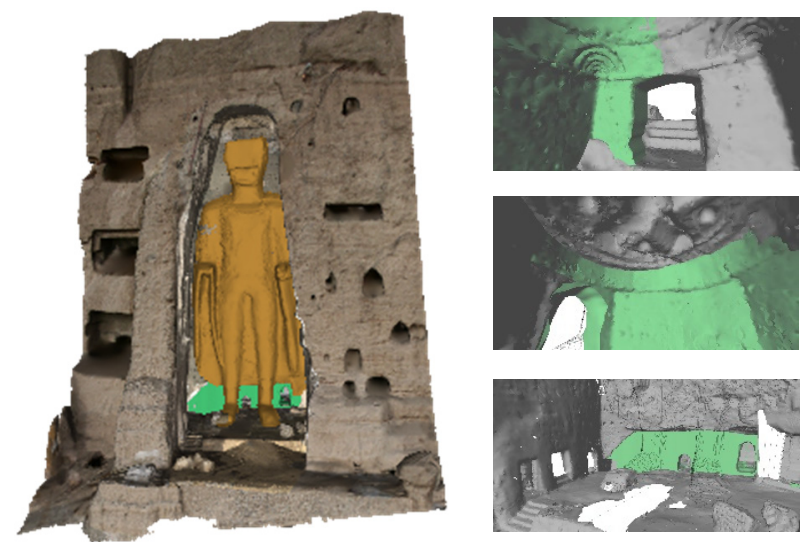

Figure 7. (left): Digital reconstruction of the $38 \mathrm{~m}$ Buddha in yellow color - (right): series of illustrations on the reconstructed cave complex in green color superposed on the digital model of the niche

The RWTH Aachen model for the $38 \mathrm{~m}$ Buddha niche allows the interaction with the various separate model parts to have the past, present and possible future spatial configuration both tested by designers and engineers, and experienced by other users of the system (Figure 7). The immersive experience, when supported by an explanatory narrative, has already proven to make the spatial conditions understandable and serves as a sound basis for scientific re-assembly proposals which make use of the original fragments. An attempt of repositioning the documented fragments in altitude is here proposed by first identifying sedimentological features of each salvaged fragment and then matching this information to the geological pattern from the rear wall of the niche. A reference profile has been documented for around half height of the rear side of the $38 \mathrm{~m}$ Buddha niche.

\footnotetext{
${ }^{6}$ Surface area calculations originate from field notes of the collected fragments and from measurements on the digital model in Autodesk 3dsMax software
}

\subsection{Repositioning of fragments based on geological and paleomagnetic patterns}

Since both Buddha figures had been originally hewn out of a conglomerate rock surface with a specific sedimentological structure, a paleo- and rock-magnetic methodology is suitable to aid in the relocation of fragments of the giant Buddha figures. Correlation of lithological details from the rear side of the Buddha niches to those of the blasted rock fragments has been tested to determine the relative position of the fragments towards the rear side of the niche. Magnetic susceptibility (i.e. the ratio of the magnetization in the rock fabric to the corresponding magnetizing force) was measured, and susceptibility profiles at a spacing of about $5-10 \mathrm{~cm}$ were determined perpendicular to the bedding of the rear niche wall (Figure 9). The combination of the rock magnetic and geologic methodology is capable of identifying the original position of fragments of the destroyed Giant Buddha figures and has elsewhere been successfully tested in the field for fragments larger than 1m (Urbat, 2009).
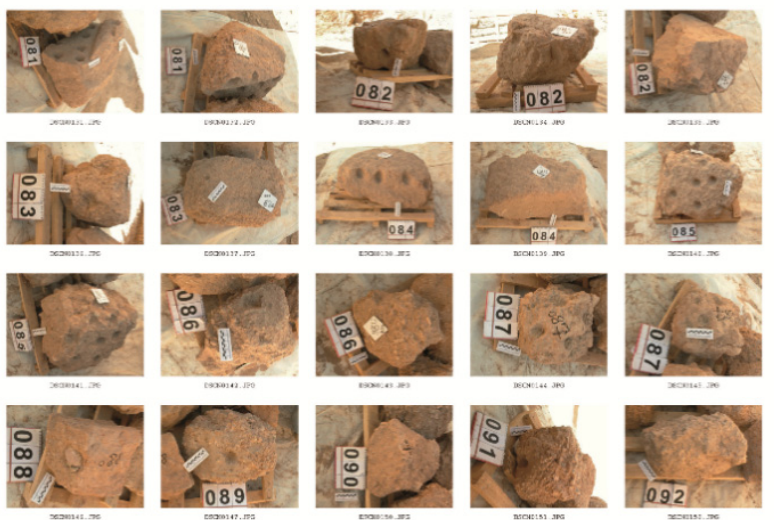

Figure 8. Example of salvaged fragments originating from the $38 \mathrm{~m}$ Buddha with visible sculptured rock surface

A total of 420 individual fragments showing traces of original surface from the $38 \mathrm{~m}$ Buddha figure could be recovered during the safeguarding campaign, featuring different lithological compositions and varying dimensions of $30 \mathrm{~cm}$ up to $180 \mathrm{~cm}$ in diameter. Of the documented fragments around $56 \%$ are rather compact in size not exceeding $110 \mathrm{~kg}$ weight (half of these pieces do not exceed $55 \mathrm{~kg}$ ) another $32 \%$ vary in size and weight up to approximately half a ton and $9 \%$ make up larger pieces up to two tons (Toubekis, 2008). The remaining portion consists of individual very big pieces which due to their size and weight between 3-20t could not be removed from the niche. The majority of the fragments could be stored in protective shelters close to the niche, whereas the largest and heaviest ones, due to their very delicate state of conservation remained in the niche under individually constructed canopies. Artificial indents in the original sculptured rock surface (Figure 8) indicate the previous orientation of the material. Altogether these fragments make around $65 \mathrm{~m}^{2}$ of recovered surface material, roughly $12 \%$ of the ca. $550 \mathrm{~m}^{2}$ total envelope surface ${ }^{6}$ of the digitally reconstructed $38 \mathrm{~m}$ Buddha.

The values for the total volume stay in the same range $(\sim 11 \%)$. According to the restorers, the recovered surface material at the site of the Western $(55 \mathrm{~m})$ Buddha might reach higher rates, but here, precise figures are not yet determined. It must be clearly stated, that at least for the site of the $38 \mathrm{~m}$ Buddha niche, the 
remaining original rock material altogether constitutes only a very small fraction of the previous total surface/volume of the destroyed figure. The absence of this vast amount of original material and the yet unsolved matter of its structural stability mark the challenges that any intervention at the site has to address in the future.

\section{CONCLUSION}

Documentation and interpretation material produced in research activities such as photographs, drawings, and digital representations help to facilitate the understanding of a monument's values from various points of view. The request of the Venice Charter to hand significant places of the Past over to future generation "in the full richness of their authenticity" has long been associated with the physical materiality of the place until the Nara Document has introduced a broader notion of authenticity to heritage practice worldwide.

Cultural Heritage has become a key asset during conflict and also post-conflict situations. The case of Bamiyan appeals urgently that debate about reconstructing heritage places is missing a key point when it is merely focused on the matter of material design and available resources - since it is the re-visioning and reconstruction of people's identities that is essential in this process.

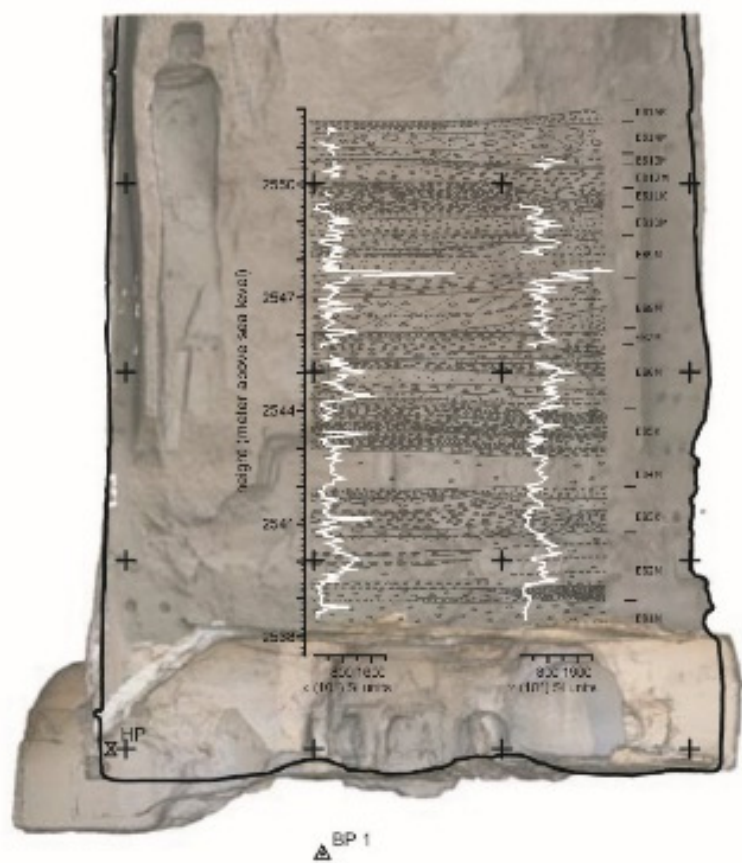

Figure 9. Geological Mapping of the rear side of the $38 \mathrm{~m}$ Eastern Buddha niche (Urbat 2009)

The question of reconstruction of destroyed heritage places has a complex impact on post-conflict recovery processes within an affected country. The motivation to pursue a partial or complete reconstruction of at least one of the destroyed Buddha figures is very strongly felt in the Valley and put forward by a local community who was marginalized in history due to nationwide ethnic and religious differences. It can be interpreted as an incubator for a convalesced self-esteem, or simply as a promoter for tourism in this region which to date has been spared from the violent conflict going on elsewhere in the country.

It is for the sake of the success of this envisioned goal, that rebuilding an important heritage symbol contributes in peace processes, reconciliation, and the rebuilding of society in the widest sense. Therefore digital simulations experienced in immersive VR environments bear the chance to avoid simplistic approaches or misinterpretation of scientific facts, resulting in counter-productive results. Considering that the notion of authenticity is culturally mediated and involves complex networks of relationships between people, places, things and concepts, this paper claims that digital reconstructions and physical replicas can acquire authenticity depending on their modes of production and consumption, and the networks of institutional and individual relations from which they arise.

\section{ACKNOWLEDGEMENTS}

We thank Prof. Torsten W. Kuhlen of the Virtual Reality Research Center at RTHW Aachen for the support he gave to this study so far and especially M.Sc. Andrea Böntsch for scheduling access to the aixCave system and M.Sc. Fabian Lennartz for programming the navigation of the VR scene.

\section{REFERENCES}

ACDC, 2007. Bamiyan Cultural Master Plan - Reports from Field Survey 2005-2007 within Phase II of the UNESCO/JFIT project - Safeguarding of the Bamiyan Site. Aachen Center for Documentation and Conservation, Aachen.

ACDC, Toubekis, G., Jansen, M., 2013. Bamiyan 2012. Damage assessment of Shahr-e Zohak (Bamiyan, Afghanistan), Technical Report prepared for UNESCO within phase IV of the UNESCO/JFIT project - Safeguarding of the Bamiyan Site, Aachen Center for Documentation and Conservation, Aachen.

ACDC, Toubekis, G., Jansen, M., 2011. Survey and Damage assessment 2010 of Shahr-i Gholghola (Bamiyan, Afghanistan) Technical report prepared for UNESCO within phase III of the UNESCO/JFIT project - Safeguarding of the Bamiyan Site, Aachen Center for Documentation and Conservation, Aachen.

Almagro Vidal, A., Ramírez González, I., Clemente San Román, C., 2015. When the virtual influences reality. The conservation project of the Toledo Gate in Ciudad Real (Spain). In: The International Archives of Photogrammetry, Remote Sensing and Spatial Information Sciences, Taipei, Taiwan, Vol. XL-5/W7, pp. 21-27.

Archaeological Survey of India, 2002. Bamiyan - Challenge to World Heritage. Special Publications ASI, Dehli, India.

Beal, S., 1884. Si-yu-ki, Buddhist Records of the Western World. Trübner, London.

Behr, K.-M., Nosper, A., Klimmt, C., Hartmann, T., 2005. Some Practical Considerations of Ethical Issues in VR Research. Presence: Teleoperators and Virtual Environments, 14(6), pp. 668-676.

Canciani, M., Falcolini, C., Buonfiglio, M., Pergola, S., Saccone, M., Mammì, B., Romito, G., 2013. A method for virtual anastylosis: The case of the Arch of Titus at the Circus Maximus in Rome. In: ISPRS Annals of the Photogrammetry, Remote Sensing and Spatial Information Sciences, Strasbourg, France, Vol. II-5/W 1, pp.61-66.

Godard, A., Godard, Y., Hackin, J. (Eds.), 1928. Les Antiquités Bouddhiques de Bāmiyān. Mémoires de la Délégation Archéologique en Afghanistan Tome 2. Van Oest, Paris.

Grün, A., Remondino, F., Zhang, L., 2004. Photogrammetric Reconstruction of the Great Buddha of Bamiyan, Afghanistan. The Photogrammetric Record, 19(107), pp. 177-199. 
Grün, A., Hanusch, T., 2008. Image- and model-based reconstruction of the Small Buddha of Bamiyan, Afghanistan. In: The International Archives of Photogrammetry, Remote Sensing and Spatial Information Sciences, Beijing, China, Vol. XXXVII/B5, pp. 963-968.

Hackin, J., Carl, J. (Eds.), 1933. Nouvelles Recherches Archéologiques à Bamiyan. Mémoires de la Délégation Archéologique en Afghanistan Tome 3, Van Ouest, Paris.

Higuchi, T., 1984. Bamiyan. Art and Archaeological researches on the Buddhist cave temples in Afghanistan 1970-78. Dohosha.

Higuchi, T., Barnes, G., 1995. Bamiyan: Buddhist Cave Temples in Afghanistan. World Archaeology. 27(2), pp.282-302.

ICOMOS, 2016. Report on the ICOMOS Advisory Mission to Cultural Landscape and Archaeological Remains of the Bamiyan Valley. In: The Giant Buddhas of Bamiyan II. Safeguarding the Remains 2010-2015, Bäßler, Berlin, pp. 245-269.

Jansen, M., Toubekis, G., Walther, A., Döring-Williams, M., Mayer, I., 2008. Laser scan measurement of the niche and virtual 3D representation of the Small Buddha in Bamiyan. In: Layers of Perception: Proceedings of the 35th International Conference on Computer Applications and Quantitative Methods in Archaeology (CAA), Habelt, Bonn, Germany, pp. 83-90.

Japan Center for International Cooperation in Conservation (Ed.), 2005. Preserving Bamiyan. Proceedings of the International Symposium "Protecting the World Heritage Site of Bamiyan" Tokyo, 21 December 2004

Landes, T., Kuhnle, G., Bruna, R., 2015. 3D modeling of the Strasbourg's Cathedral basements for interdisciplinary research and virtual visits. In: The International Archives of Photogrammetry, Remote Sensing and Spatial Information Sciences, Taipei, Taiwan, Vol. XL-5/W7, pp. 263-270.

Margottini, C., Colombini, V., Crippa, C., Tonoli, G., 2005. Emergency Intervention for the Geo-Mechanical Conservation of the Niches of Bamiyan Buddhas (Northern Afghanistan). In: Landslides. Risk Analysis and Sustainable Disaster Management. Springer, Berlin Heidelberg, pp. 75-79.

Margottini, C. (Ed.), 2014. After the destruction of giant Buddha statues in Bamiyan (Afghanistan) in 2001: A UNESCO's emergency activity for the recovering and rehabilitation of cliff and niches. Springer, New York.

Metzger, M.J., Flanagin, A.J., 2013. Credibility and trust of information in online environments: The use of cognitive heuristics. Journal of Pragmatics 59, pp. 210-220.

Petzet, M., 2016. Various proposals for remedial measures and the future presentation of the two Buddha niches (Paris, 3 March 2011). In: The Giant Buddhas of Bamiyan II, Bäßler, Berlin, pp. 83-99.

Petzet, M. (Ed.), 2009. The Giant Buddhas of Bamiyan. Safeguarding the Remains. Bäßler, Berlin.

Petzet, M., 2002. Anastylosis or Reconstruction - the conservation concept for the Remains of the Buddhas of Bamiyan. In: Strategies for the World Heritage. Preservation in a Globalized World. Proceedings of ICOMOS Spain for the ICOMOS 13th General Assembly. Madrid, pp. 189-192.
Santana, M., 2002. Report on the UNESCO/ICOMOS mission to Bamiyan 2002, Aachen Center for Documentation and Conservation, Aachen.

Toubekis, G., 2008. Kleiner Buddha - Dokumentation Fragmente (Fieldwork July-October 2006). In: ICOMOS Project Afghanistan. Preservation of the Buddha Fragments in Bamiyan. Reports 2006-2007-2008, Aachen Center for Documentation and Conservation, Aachen.

Toubekis, G., 2009. 3D Laser Scanning and Post-Processing of the Niche of the Eastern Buddha, 2006. In: The Giant Buddhas of Bamiyan: Safeguarding the Remains, Michael Petzet (Ed.), Bäßler, Berlin, pp. 117-122.

Toubekis, G., Mayer, I., Döring-Williams, M., Maeda, K., Yamauchi, K., Taniguchi, Y., Morimoto, S., Petzet, M., Jarke, M., Jansen, M., 2011. Preservation and Management of the UNESCO World Heritage Site of Bamiyan. In: CIPA Heritage Documentation: Best Practise and Applications; CIPA Symposium 2007-2009, Kyoto, Japan, pp. 93-100.

Urbat, M., 2009. A combined geological and Paleomagnetic approach towards the repositioning of fragments from the Buddha Statues. In: The Giant Buddhas of Bamiyan: Safeguarding the Remains, Bäßler, Berlin, pp. 89-102.

UNESCO, 2017. The Future of the Bamiyan Buddha Statues. Technical Considerations and Potential Effects on Authenticity and Outstanding Universal Value. Organized by the Government of the Islamic Republic of Afghanistan and UNESCO https://bamiyanfuture.com/ (accessed 21.02.2017)

UNESCO World Heritage Centre, 2011. World Heritage Committee - Decision - 35 COM 7A.25, http://whc.unesco.org/en/decisions/4359 (accessed 22.02.2017).

Yamauchi, K., Suzuki, T. (Eds.), 2013. Structure, Design and Technique of the Bamiyan Buddhist Caves. Archetype Publications Ltd, London.

Yamauchi, K., Suzuki, T., Kondo, H. (Eds.), 2012a. Documentation of the Bamiyan Sites 1 - Cultural Landscape of the Central Part of the Bamiyan Valley in the 1970's. Recent Cultural Heritage Issues in Afghanistan Suppl. 4, Japan Center for International Cooperation in Conservation, NRICPT, Tokyo.

Yamauchi, K., Suzuki, T., Kondo, H. (Eds.), 2012b. Documentation of the Bamiyan Sites 2 - Topographic Survey of the Central Part of the Bamiyan Valley. Recent Cultural Heritage Issues in Afghanistan Suppl. 5, Japan Center for International Cooperation in Conservation, NRICPT, Tokyo.

Yamauchi, K., Suzuki, T., Kondo, H., Ito, Y., Nakamura, H. (Eds.), 2013. Documentation of the Bamiyan Sites 3 Conservation of the Mural Paintings of the Bamiyan Buddhist Caves. Recent Cultural Heritage Issues in Afghanistan Suppl. 6, Japan Center for International Cooperation in Conservation, NRICPT, Tokyo.

Yamauchi, K., Suzuki, T., Iwade, M., Kubodera, S., Kondo, H., Nakamura, H., Ito, Y. (Eds.), 2014. Documentation of the Bamiyan Sites 4 - Architectural Survey of the Bamiyan Buddhist Caves. Recent Cultural Heritage Issues in Afghanistan Suppl. 7, Japan Center for International Cooperation in Conservation, NRICPT, Tokyo. 